\title{
A formação do formador de professores: perspectivas de colaboração entre graduandos e pós-graduandos no projeto Teletandem Brasil ${ }^{1}$
}

\author{
The education of teacher educators: \\ perspectives of collaboration between \\ undergraduate and graduate students in the \\ Project Teletandem Brazil
}

Ana Cristina Biondo Salomão*

Universidade Estadual Paulista - UNESP

São José do Rio Preto - São Paulo / Brasil

\begin{abstract}
RESUMO: Este artigo apresenta os resultados de um estudo qualitativo realizado no projeto Teletandem Brasil sobre os processos de supervisão e estratégias pedagógicas utilizadas por uma mediadora no processo de mediaçáo de um par interagente. Baseando-nos no paradigma da formação reflexiva, na teoria sociocultural de Vygotsky e na aprendizagem colaborativa de línguas, com especial ênfase para o regime tandem, analisamos as contribuições da relação colaborativa formada entre uma aluna de pós-graduação e uma aluna-professora em formação. Os resultados trazem implicações para o campo da formação de professores de línguas, em relação a uma perspectiva de formação na prática, evidenciando a experiência de ensino e aprendizagem colaborativos no Teletandem como uma oportunidade para a formação reflexiva do aluno-professor, o interagente, e também do futuro formador de professores, o mediador.
\end{abstract}

PALAVRAS-CHAVE: Formação de professores, aprendizagem colaborativa, Teletandem, mediação

\footnotetext{
* e-mail da autora

${ }^{1} \mathrm{O}$ artigo apresenta parte dos resultados da pesquisa de Mestrado intitulada "Gerenciamento e estratégias pedagógicas na mediação dos pares no Teletandem e seus reflexos para as práticas pedagógicas dos interagentes" (2008), orientada pela Profa. Dra. Maria Helena Vieira Abrahão.
} 


\begin{abstract}
In this article, we present some of the results of a qualitative research within the Project Teletandem Brazil about the process of supervision and pedagogic strategies used by a mediator in the mediation process of a pair of Teletandem partners. Based on the reflexive teaching paradigm, on Vygotsky's sociocultural theory and on collaborative language learning, with special emphasis to tandem learning, we analyzed the contributions of the collaborative relationship established between a graduate student and a student-teacher. The results bring about implications to the field of language teacher education, in relation to a perspective of education within practice, evidencing the experience of collaborative learning in Teletandem as an opportunity for reflexive teacher education for both the student-teacher and the future teacher educator.
\end{abstract}

KEYWORDS: Teacher education, collaborative language learning, Teletandem, mediation.

\title{
Introdução
}

Nos últimos anos, muitas pesquisas sobre o ensino e aprendizagem de línguas têm se focado na formação de professores, tanto inicial como continuada. Vários autores têm apontado o aumento de interesse de pesquisadores e professores por essa área, como Gil (2005), Gimenez (2004b), Vieira-Abrahão (2004, 2006), e buscado uma avaliação e reestruturação dos cursos de Letras em nosso país, como Paiva (2004, 2005), Gimenez (2005a, b). Esse interesse revela que as pesquisas têm dado mais espaço para o ensino de língua estrangeira sob a ótica do professor e que a formação (inicial ou em serviço) é "objeto relevante de investigação" (GIMENEZ, 2004a, p. 171).

Entretanto, em nossas buscas por referenciais teóricos, notamos que muito pouco tem sido dito sobre a formação (inicial ou continuada) dos formadores de professores, ou seja, dos docentes em cursos de graduação ou pós-graduação em Letras que se encarregam da formação destes profissionais. Muitas vezes o aluno acaba de sair da pós-graduação e vai atuar como professor em um curso de Letras pela primeira vez, sem ter nunca trabalhado com formação de professores. Além disso, é comum que ele tenha enfocado em sua pesquisa de pós-graduação aspectos sobre o ensino de línguas que não necessariamente conduzem à transposição direta de suas novas funções e às necessidades de alunos-professores em formação.

Em nossa pesquisa de mestrado (SALOMÃO, 2008), estudamos o papel de uma aluna de pós-graduação, nível de mestrado, denominada mediadora dentro de uma relação de Teletandem, por meio da análise das estratégias pedagógicas utilizadas por ela ao conduzir a mediação com uma interagente (uma aluna de graduação), a qual ela supervisionava. Nosso projeto 
se inseriu no projeto de pesquisa Teletandem Brasil, na área de ensino de línguas estrangeiras a distância, da UNESP (São José do Rio Preto e Assis), que objetiva colocar alunos universitários brasileiros e estrangeiros (denominados pares interagentes) em contato para trabalho colaborativo na tarefa de ensinar e aprender línguas a distância, por meio de mensageiros eletrônicos, como o Live Messenger, o Skype, o Oovoo, com seus recursos de áudio, vídeo e escrita. Desse modo, cada interagente, falante nativo ou proficiente em um idioma ensina-o ao outro. O projeto envolve o ensino e aprendizagem de línguas, assim como a pesquisa acadêmica, na qual estão envolvidos pesquisadores da área da Linguística Aplicada, alunos de pós-graduação, graduação e iniciação científica.

Os mediadores são alunos de pós-graduação em Estudos Linguísticos - doutorandos e mestrandos - da UNESP, que se encarregam de supervisionar e auxiliar, por meio de encontros presenciais ou virtuais, os pares de interagentes tanto na aprendizagem quanto no ensino de línguas que ocorre nessa relação. Desse modo, a figura do mediador é assim chamada por se tratar de um par mais competente que irá mediar, nos termos vygotskianos, a aprendizagem do interagente, oferecendo-lhe a mediação por instrumentos, incluindo-se aí os recursos tecnológicos ou não utilizados por ele, e a mediação por meio do uso da linguagem dentro da interação que ocorrerá nas sessões em que debaterão aspectos da relação de ensino e aprendizagem na qual se insere o interagente.

Nossa intenção neste artigo é discutir o processo de mediação pedagógica dentro do Teletandem e suas influências para a formação da própria mediadora, uma aluna de pós-graduação (formadora de professores em formação) inserida em um contexto de prática como formadora de professores pela primeira vez. Para tal, primeiramente, explicitamos as propostas de aprendizagem colaborativa, com especial ênfase para o regime tandem, e, então, apresentamos a proposta de Teletandem, examinando os princípios que o norteiam, assim como os conceitos de interação e mediação presentes em tal contexto. Posteriormente, trazemos um recorte da análise dos dados de nossa pesquisa de mestrado que ilustram o processo de mediação e suas influências no processo de formação inicial da mediadora. Por fim, tecemos nossas considerações.

\section{A aprendizagem colaborativa em regime de tandem}

Tandem é nome dado àquelas bicicletas que possuem dois bancos e dois conjuntos de pedais, na qual os dois usuários de tal veículo devem trabalhar em conjunto para que consigam atingir o objetivo de fazê-la andar. No caso 
do ensino e aprendizagem, essa relação se torna também colaborativa, exigindo trabalho em conjunto, uma vez que cada um dos parceiros torna-se aprendiz da língua estrangeira do outro e tutor de sua própria língua.

Originalmente, segundo Vassallo e Telles (2006), a concepção de aprendizagem in-tandem surgiu na Alemanha nos anos 60 e baseou-se na promoção de parcerias entre aprendizes de línguas estrangeiras, que falavam idiomas diferentes, visando à aprendizagem da língua uns dos outros. Os autores explicam que foi somente na década de 1970, na Espanha, que o nome Tandem passou a ser usado da maneira como é feito hoje para denominar essa modalidade de aprendizagem de línguas, e a sistematização de seus princípios ocorreu realmente durante a década de 1990.

De acordo com Panichi (2002), citando Brammerts (1996), do ponto de vista teórico, os princípios fundamentais que subjazem à parceria dos aprendizes em regime de tandem são: o princípio da igualdade (ou bilinguismo), da reciprocidade e da autonomia. O primeiro estabelece que as sessóes de tandem devem ser compostas de duas partes, e cada participante da parceria deve comprometer-se a usar a língua estrangeira, da qual ele é aprendiz, e sua língua materna, mas nunca em uma mesma sessão. Segundo Vassallo e Telles (2006), as línguas não podem ser misturadas, e, por isso, os autores chamam este princípio de separação das línguas. Esse princípio está ligado à contribuição ativa e aos resultados individuais e conjuntos que devem ser obtidos dentro de uma relação de aprendizagem colaborativa de sucesso, mencionados por Kohonen (1992). Os princípios da autonomia e da reciprocidade juntos estabelecem que cada aluno será responsável por seu próprio processo de aprendizagem e pela aprendizagem do outro, e ambos devem trabalhar em conjunto para delimitarem seus objetivos e escolherem quais serão os melhores métodos para alcançá-los - a interdependência positiva de Kohonen (1992). Desse modo, a aprendizagem em tandem caracteriza-se pelo fato de ser, simultaneamente, uma experiência de aprendizagem autônoma, mas fundamentalmente colaborativa (SOUZA, 2006).

No que tange às modalidades do tandem, inicialmente, ele surgiu como tandem face a face, realizado de modo presencial, com os parceiros se reunindo em um mesmo espaço físico para realizarem suas atividades de ensino e aprendizagem. Com o surgimento dos avanços tecnológicos da comunicação eletrônica, uma nova modalidade foi desenvolvida, o $e$-tandem, permitindo que os pares se comuniquem através de espaços físicos e geográficos diferentes para realizarem as atividades de ensino e aprendizagem. 
Vassallo e Telles (2006) afirmam que no Brasil o tandem foi escassamente praticado em sua modalidade face a face, devido a dificuldades de encontros entre falantes nativos de diferentes línguas e de mobilidade por diferentes países, como ocorre na Europa, onde o tandem surgiu e se tornou bastante popular, especialmente em contextos acadêmicos. Os autores afirmam, entretanto, que a expansão da Internet e do uso de e-mails para a comunicação entre as pessoas trouxeram popularidade ao regime de tandem para o ensino de línguas mediado por computador no país e que os avanços tecnológicos da comunicação síncrona abriram novas possibilidades de interação para sessões de tandem a distância.

Caracterizaremos a seguir a modalidade de Teletandem, adotada no projeto Teletandem Brasil: linguas estrangeiras para todos.

\section{O Teletandem}

A modalidade de Teletandem, proposta por Vassallo e Telles (2006) e Telles e Vassallo (2006), sugere que os parceiros de tandem façam uso do aspecto oral e escrito por meio de chats e conferências em áudio e vídeo, utilizando-se de comunicadores eletrônicos síncronos.

Telles e Vassallo (2006) contam que a ideia dessa nova modalidade de tandem surgiu quando, após algum tempo praticando tandem face a face no Brasil, Vassallo teve que voltar para a Itália, e assim ambos tiveram que buscar novas formas para estabelecer comunicação. A princípio, optaram pelo $e$ tandem, via $e$-mail. Entretanto, sentiam falta da interação oral, visto que este meio somente possibilitava a produção escrita e a leitura. Sua busca os levou às ferramentas de comunicação instantânea na Internet, como o MSN Messenger, ou em sua versão mais atual, o Windows Live Messenger. Os autores afirmam que, ao testarem essa ferramenta para a aprendizagem em tandem entre si e com amigos, notaram que os resultados foram divertidos, práticos e, acima de tudo, de baixo custo. Assim, surgiu o projeto Teletandem Brasil: línguas estrangeiras para todos, com o intuito de investigar as ramificaçóes do modo de aprendizagem que estavam experimentando e seus possíveis resultados para a educação de línguas.

Segundo os autores, o Teletandem possui as mesmas características e princípios da aprendizagem em regime de tandem, a não ser pela diferença que o tandem face a face é restrito a pessoas que se encontram no mesmo local geográfico e o e-tandem está confinado às habilidades de leitura e escrita, enquanto que o Teletandem conjuga as quatro habilidades: produção oral, 
compreensão oral, leitura e escrita, sem que as pessoas estejam necessariamente no mesmo local. Para Telles e Vassallo (2006), é o enfoque em uma reflexão sobre a língua, o ensinar e o aprender, que diferencia o Teletandem de um batepapo informal.

\section{Interação e mediação no Teletandem}

Baseando-se em suas experiências pessoais como praticantes de Teletandem, Telles e Vassallo (2006) também propuseram algumas diretrizes para uma sessão de teletandem, denominada dentro do projeto de 'interação'. Tais diretrizes aconselham que uma sessão prototípica seja composta de duas horas, uma para cada língua (feitas no mesmo dia, ou em dias separados), sendo cada hora composta das seguintes fases: conversação sobre um ou vários assuntos (cerca de 30 minutos); feedback linguístico (cerca de 20 minutos); e reflexão compartilhada na sessão (aproximadamente 10 minutos).

As sessões de mediação configuram-se como encontros entre o interagente (aluno universitário praticante de Teletandem) e o mediador (aluno de pós-graduação), para que possam discutir aspectos relacionados à prática do interagente e refletir juntos sobre as dúvidas, os problemas encontrados no ensino e aprendizagem de línguas nas sessões de Teletandem, questôes culturais, possíveis impasses. O mediador se coloca para o interagente como um parceiro de discussão, fazendo, assim, a intermediação da aprendizagem segundo pressupostos vygotskianos, de desenvolvimento por meio da interação social e por meio do oferecimento de andaimes. Essas estruturas de apoio, segundo Vygotsky (1981, apud FIGUEIREDO, 2006), conduzirão o indivíduo da regulação pelo objeto - pelo ambiente, contexto - e da regulação pelo outro - auxílio do mais capaz - para a autorregulação, ou seja, para a atividade intrapsicológica, desenvolvendo estratégias para realizar as tarefas de modo independente. Assim, não é o ato de desempenhar a tarefa que configura a característica importante da atividade interpessoal, mas o processo cognitivo superior que emerge como resultado da interação (LANTOLF, 1994).

A função dos mediadores está sendo estudada no decorrer do projeto. Tal figura dentro da relação de Teletandem foi sugerida devido às propostas de aconselhamento já existentes dentro do regime de aprendizagem em tandem, como as propostas de sessóes de aconselhamento individual, feitas por uma pessoa cuja especialidade seja ensino e aprendizagem de línguas (BRAMMERTS; CALVERT; KLEPPIN, 2003; STICKLER, 2003); sessôes de aconselhamento em pares (HELMLING, 2003), nas quais os próprios participantes 
aconselham outros participantes, de diferentes parcerias, e o uso de diários semiestruturados que fomentem a autonomia (WALKER, 2003). Tais propostas enfocam a perspectiva do aprendiz na relação de aprendizagem em tandem, restringindo-se a auxiliar o aluno na tarefa de aprender a língua estrangeira, incentivando-o a aprender de maneira independente, a refletir sobre seus processos de aprendizagem, decidindo seus objetivos e continuamente revisando-os, e a avaliar seu progresso.

A ideia de mediação em vez de aconselhamento trazida pelo projeto Teletandem entende o auxílio prestado pela figura do mediador não somente como conselhos sobre como proceder para aprender melhor mas como uma pessoa que se insere na relação de ensino e aprendizagem colaborativos da parceria de interagentes para auxiliá-los a refletir sobre sua própria prática enquanto aprendizes da língua do outro e professores de sua própria língua. O termo mediador é usado, desse modo, por estar intimamente ligado às ideias de Vygotsky em sua teoria social do conhecimento, que expóe a possibilidade de o homem, por meio de suas relações sociais e da linguagem, constituir-se e desenvolver-se como sujeito (FREITAS, 2000).

\section{Reuniões para discutir as diretrizes das mediações}

Foram realizadas, antes do início das mediações, reuniões entre os mediadores os e coordenadores do projeto com o objetivo de discutir algumas diretrizes para a sua atuação. As reuniōes foram norteadas pelas leituras prévias dos textos de Korthagen (1982) - "Helping student teachers to become reflective: the supervision process" - e Sól (2005) - "Modelos de supervisão e o papel do formador de professores", os quais trazem perspectivas de reflexão para professores e formadores de professores.

Como muitos dos mediadores, alunos de mestrado e doutorado, nunca haviam trabalhado com formação de professores, acreditou-se que tal preparação seria interessante para que eles entrassem em contato com teorias que trouxessem uma visão de formação voltada à reflexão. E, assim, foi elaborada pelo próprio grupo de mediadores uma proposta de "diretrizes" para a mediação, que foi publicada no Newsletter do grupo de pesquisa, que é apresentada a seguir: 


\section{QUADRO 1}

As quinze diretrizes para a mediação

\section{SERIA INTERESSANTE E PERTINENTE SE O PROFESSOR-MEDIADOR:}

1- estabelecesse uma boa relação com os interagentes, de forma a criar uma atmosfera de segurança e confiança permanente entre eles;

2- promovesse uma atmosfera informal e descontraída que instigasse os interagentes a verbalizar suas ansiedades, suas necessidades e dificuldades, sem constrangimentos ou receios;

3- tentasse diminuir a assimetria entre ele e os interagentes, pois ambos deveriam ser "cúmplices" nesse processo de ensinar e aprender virtualmente, trabalhando colaborativamente a fim de atingir um objetivo em comum;

4- procurasse não prescrever um modo que ele acredita estar correto, evitando realizar, assim, uma prática pedagógica diretiva que impossibilitasse a reflexão e autonomia do aprendiz;

5- negociasse constantemente com os interagentes com relação aos horários de mediaçôes; à produção e entrega de dados de pesquisa; ao tipo de recursos do MSN Messenger utilizados durante a mediação (câmera, áudio etc.), entre outros;

6- partisse sempre das necessidades dos interagentes, vivenciadas em sua prática;

7- não condenasse a prática pedagógica do interagente, para não baixar a sua autoestima e não fazer com que ele se sinta incapaz e inferior aos demais;

8- sugerisse, pelo menos em um primeiro momento, alternativas para que o aluno pudesse refletir e decidir qual seria a mais viável e adequada para ser colocada em prática;

9- avaliasse as alternativas apresentadas pelos interagentes frente a outras alternativas;

10 - fizesse uso, num segundo momento, da supervisão colaborativa, dando liberdade para que os interagentes reflitam sobre sua prática, compreendam suas açôes e desenvolvam uma maior capacidade crítica;

11 - encorajasse os interagentes, apontando os aspectos positivos e, posteriormente, realizasse reflexões a cerca de questões conflituosas;

12- colaborasse para focalizar melhor o problema e ajudasse o interagente a generalizar uma questão, caso o professor perceba que não se trata de um caso isolado, mas, sim, de um problema que persiste durante toda a sua prática;

13- procurasse não trabalhar com respostas prontas, mas, sim, instigasse o interagente a buscar o melhor caminho para que ele aprenda a refletir e encontrar, de maneira autônoma, soluções para possíveis problemas, tornando-os aptos para a resolução de situaçôes conflituosas com as quais inevitavelmente se depararão em suas experiências pedagógicas futuras;

14- não avaliasse a prática do aluno em "mau"; "melhor", "pior", pois nenhuma prática deve ser julgada, já que não existem práticas melhores ou piores do que outras, mas práticas diferentes e adequadas ou não para determinados contextos;

15- sugerisse, caso haja necessidade, leituras teóricas.

Fonte: Teletandem News, ano 1, n. 1, p. 7

Como se pode ver, as diretrizes para a mediação buscaram enfatizar o papel do mediador como fomentador de formação reflexiva, sugerindo que 
ele não fosse diretivo, mas que buscasse criar uma atmosfera de confiança e negociação, partindo das necessidades dos interagentes e utilizando-se de estratégias que envolvessem o oferecimento de alternativas, colaboração e provimento de teoria de acordo com as necessidades.

\section{Relação estudada na pesquisa}

A pesquisa enfocada neste artigo envolveu o estudo de caso (GILHAM, 2000) da relação de formação reflexiva entre uma mediadora e uma interagente brasileira, como se pode ver na FIG. 1.

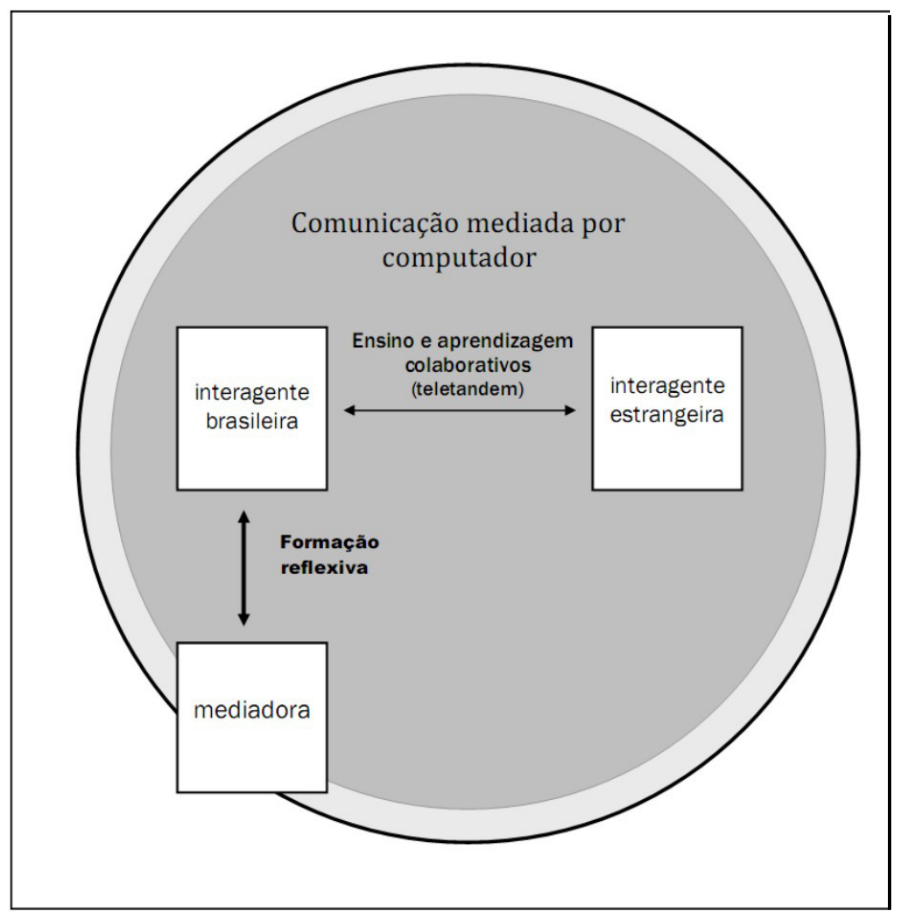

FIGURA 1 - Relação estudada na pesquisa

A mediadora está dentro e fora do ambiente virtual de aprendizagem, como pode ser visto na FIG. 1, porque os encontros entre ela e a interagente brasileira para as sessões de mediação ocorreram ora de maneira virtual, ora de maneira presencial. Outro ponto a ser salientado é o de que a relação mediadorinteragente somente ocorreu no ambiente de nossa pesquisa entre a interagente brasileira e a mediadora brasileira, pois, do lado estrangeiro, não houve a possibilidade de se contar com um mediador. A interagente argentina nos 
ajudou como colaboradora, porque o instituto no qual estudava não se adequou completamente aos requerimentos do Projeto Teletandem.

A mediadora brasileira, identificada aqui como Andréa, é graduada em Letras, licenciatura em português e espanhol, por uma universidade estadual no interior do estado de São Paulo, tinha 6 anos de experiência como professora de língua espanhola, mas nenhuma experiência com formação de professores. $\mathrm{Na}$ época do estudo, ela também era aluna do mestrado em Estudos Linguísticos da UNESP e fazia parte do projeto Teletandem Brasil como mediadora e pesquisadora. Nessa pesquisa, Andréa era vista como uma formadora de professores em formação, uma vez que o mestrado a habilitaria a dar aulas no ensino universitário, em um curso de Letras, por exemplo, e também por sua participação como mediadora de uma aluna de graduação (interagente brasileira) no projeto Teletandem.

As interagentes participantes deste estudo foram: uma aluna brasileira de graduação do segundo ano do curso de Letras em Espanhol de uma universidade estadual no interior do estado de São Paulo, identificada aqui como Dani, sem experiência como professora de línguas; e uma aluna estrangeira, estudante de um curso universitário de formação de professores de Língua Portuguesa na Argentina, com pouca experiência, tendo dado aulas de português esporadicamente para alunos particulares. Ambas afirmaram haver buscado o curso de licenciatura com a intenção de se tornarem professoras da língua estrangeira a qual estudavam, e são consideradas nesta pesquisa professoras de línguas em formação, vivenciando uma prática de ensino no Teletandem, uma vez que, ao interagir, exercem o papel de professoras, ainda que de suas próprias línguas nativas.

\section{O processo de mediação}

O processo de mediação incluiu elementos reflexivos, como visionamento, confecção de diários, assim como partiu da situação de prática vivenciada pela interagente em sua prática pedagógica dentro do Teletandem. Tal processo englobou de maneira longitudinal a dinâmica estabelecida entre mediações e interações durante todo o período de coleta de dados, 8 meses, nos quais a mediadora e a interagente brasileira se encontraram regularmente para as sessões de mediação.

No total ocorreram 22 interações e 9 mediações, cuja intercalação foi negociada entre mediadora e interagente, segundo a necessidade de ambas. $\mathrm{O}$ ciclo estabelecido começava nas interações, seguidas de visionamento e 
confecção de diários por ambas participantes, para levantamento de pontos a serem discutidos durante as sessões de mediação, sendo estas novamente seguidas de confecção de diários, e culminando na volta à interação, como podemos ver de forma mais esquemática na FIG. 2, a seguir:

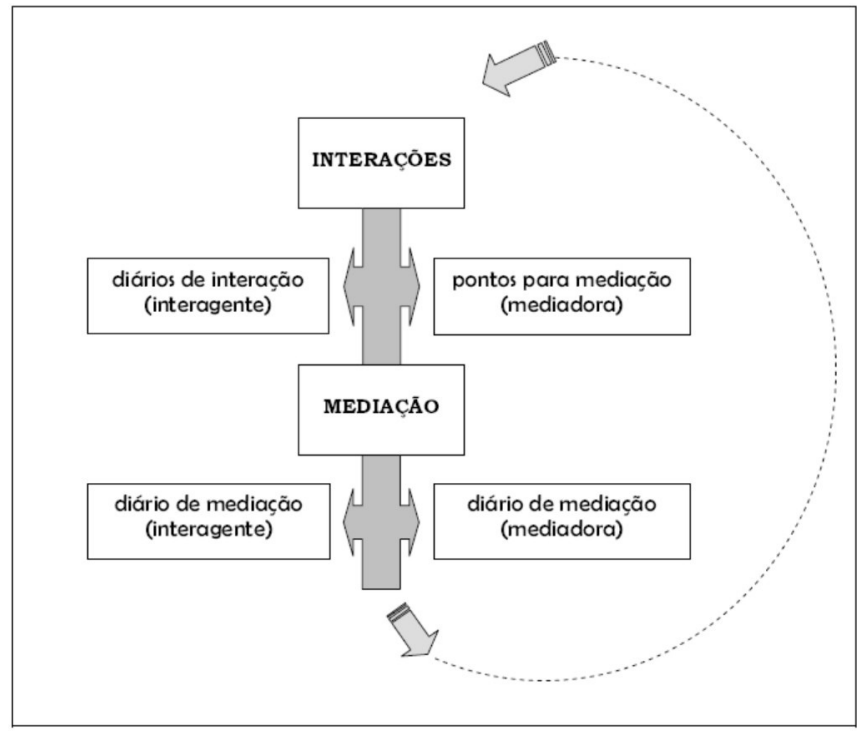

FIGURA 2 - Representação do ciclo de interações, mediações e confecção de diários

Tal ciclo das interações e mediações, visto sob uma perspectiva de macroprocesso, pareceu seguir a dinâmica sugerida pelas diretrizes da mediação, já explicitadas, assemelhando-se ao modelo de Korthagen (1982, 1999, 2001), o ALACT (Action, Looking back, Awareness, Creating alternative methods, Trial), apresentado na FIG. 3. Nesta figura, podemos observar, no interior do círculo, as fases do modelo de Korthagen, que dão origem ao nome dado a ele, e, do lado de fora do círculo, as atitudes necessárias ao formador: 


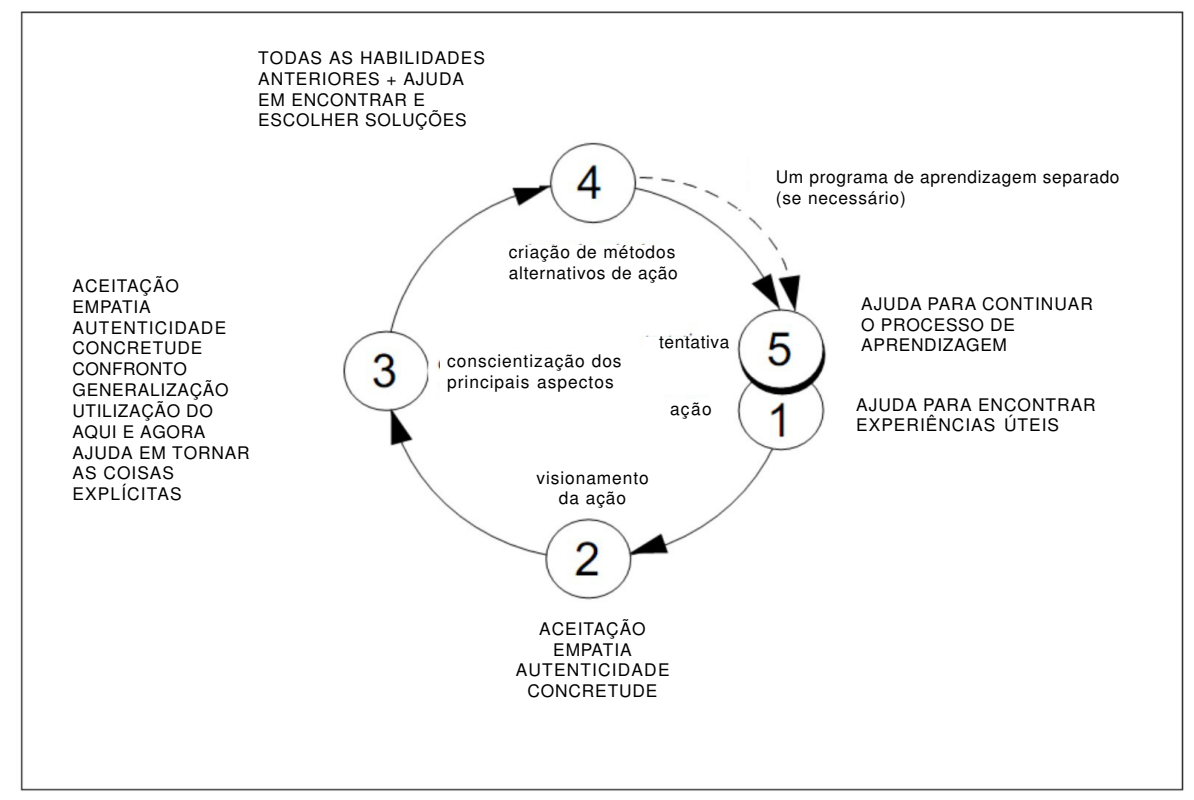

FIGURA 3 - O modelo ALACT (KORTHAGEN; KESSELS, 1999)

Das cinco fases propostas pelo autor em seu modelo cíclico de supervisão, todas foram contempladas durante a dinâmica do processo de interações e mediações no período da coleta de dados. Korthagen aconselha que se parta da prática na busca de experiências úteis (fase 1), e, por meio de visionamentos (fase 2), busque-se a conscientização sobre os principais aspectos da ação do professor-aluno (fase 3), o que foi notado no trabalho da mediadora durante os oito meses de supervisão da interagente. $\mathrm{O}$ autor também aconselha que se busquem métodos alternativos de ação (fase 4), podendo, neste momento, envolver uma volta à teoria, caso necessário, o que foi contemplado no decorrer das 3 últimas mediações. Ao final, havia, como sugerido pelo autor, um recomeço do ciclo, com a volta à ação (fase 5) em uma nova interação, dando-se continuidade ao processo reflexivo por meio da prática.

Quanto à percepção de partes de tal modelo de supervisão na dinâmica estabelecida pelas mediações, credita-se isso à abordagem da mediadora, que buscou ser uma formadora não prescritiva e trazer para a discussão, durante as mediaçóes, aspectos levantados na prática da interagente como professora $\mathrm{e}$ aluna, utilizando-se das atitudes propostas por Korthagen, como se pode ver no excerto apresentado no QUADRO 2: 
QUADRO 2

Sessão de mediação e atitudes da formadora

\begin{tabular}{|c|c|c|}
\hline & Sessão de mediação & $\begin{array}{c}\text { Atitudes } \\
\text { (segundo o modelo ALACT) }\end{array}$ \\
\hline Andréa & $\begin{array}{l}\text { Eu vi que você indaga bastante e eu achei isso legal... } \\
\text { você sempre ta perguntando, né. }\end{array}$ & concretude / aceitação \\
\hline Dani & É, hum-hum & \\
\hline Andréa & $\begin{array}{l}\text { Eu vi assim que tem hora que você corrige e tem hora } \\
\text { que você não corrige. Por que você faz isso? }\end{array}$ & $\begin{array}{l}\text { utilização do aqui e agora / } \\
\text { questionamento }\end{array}$ \\
\hline$\overline{\text { Dani }}$ & O português você fala? & \\
\hline Andréa & $\begin{array}{l}\text { É, vocês tão corrigindo, né, eu percebi ... Não, mas tudo } \\
\text { bem ... é porque ... só quero saber mesmo assim o que } \\
\text { você acha mesmo assim tudo, não tem problema ... é } \\
\text { porque eu percebi que tem hora que você corrige e tem } \\
\text { hora que não e tem hora que você corrige em caixa } \\
\text { alta, né? }\end{array}$ & aceitação / concretude \\
\hline Dani & $\begin{array}{l}\text { então é, eu percebi também, e depois daquele dia da } \\
\text { reunião que alguém falou da caixa alta sabe? Daí eu } \\
\text { não sei se é bom eu deixar assim ou corrigir normal. }\end{array}$ & \\
\hline Andréa & $\begin{array}{l}\text { Não, aí é uma opção. Você lembra daquela reunião que } \\
\text { a gente teve lá que falou os tipos de correções e tudo? } \\
\text { Qual tipo de correção você acha que está fazendo? } \\
\text { Você sente assim que você faz? Que tinha aquela que a } \\
\text { gente corrige na hora, aquela que a gente reformula, } \\
\text { aquela que a gente pergunta. Qual você acha que você } \\
\text { faz mais? }\end{array}$ & $\begin{array}{l}\text { ajuda para tornar as coisas } \\
\text { explícitas }\end{array}$ \\
\hline Dani & $\begin{array}{l}\text { Assim, tem algumas vezes que ela coloca assim alguma } \\
\text { coisa errada, aí eu reformulo de novo como reposta, sabe? }\end{array}$ & \\
\hline Andréa & Hum-hum & $\begin{array}{l}\text { mostrando que está engajada } \\
\text { na conversa }\end{array}$ \\
\hline$\overline{\text { Dani }}$ & $\begin{array}{l}\text { Aí eu coloco a palavra correta, tentando que ela ve/ } \\
\text { assim... pensando assim que ela vai ver como eu to } \\
\text { escrevendo... }\end{array}$ & \\
\hline Andréa & Hum, tá & aceitação \\
\hline Dani & e ela vai ver que ela errou, entendeu? & \\
\hline Andréa & E você acha que ela consegue perceber, ou não? & confronto \\
\hline$\overline{\text { Dani }}$ & Então, aí eu não sei, né. & \\
\hline
\end{tabular}

Podemos ver que as atitudes de Andréa buscam criar um clima de confiança e aceitação ao trazer questôes da prática da interagente para discussão. Sua preocupação com não ser diretiva fica evidenciada, uma vez que ao em vez de apontar diretamente as falhas ou inadequações vistas durante as interações, ela opta por questionar a interagente sobre tais pontos. 
A dinâmica em tal relação de mediação dentro do Teletandem, com a sessão de mediação, os visionamentos, a experiência prática de interação, inserção de teoria e confecção de diários, pareceu gerar oportunidades para reflexão por meio dos andaimes oferecidos não somente para a interagente mas também para a mediadora, como discutiremos a seguir. ${ }^{2}$ Tal percepção nos leva a refletir sobre a mediação não somente como um auxílio para o par menos competente mas também como uma relação multidirecional, na qual todos os envolvidos são influenciados pelo processo.

\section{Reflexos do macroprocesso para a prática da mediadora}

A mediadora, como já dito, era uma aluna de mestrado, e, portanto, uma formadora de professores em processo de formação, e a experiência dentro do Teletandem, mais especificamente neste estudo de caso, pareceu gerar também reflexos para a sua própria formação reflexiva. Os reflexos mais salientes percebidos se relacionaram à sua busca de uma construção da prática a partir dos resultados percebidos e às reflexões sobre suas próprias crenças sobre ensino e aprendizagem de línguas.

\section{Construção da prática de mediação a partir dos resultados percebidos}

O visionamento das sessões feito por Andréa ficou claro desde o início, uma vez que em seus diários de preparação para a mediação ela listava pontos levantados a partir das sessões de interação, buscando na prática da interagente aspectos a serem discutidos na sessão.

No primeiro questionário, respondido antes do início das mediações, ao ser questionada sobre o papel do mediador e de como ela pretendia se preparar para as sessões de mediação, a mediadora afirmou preocupar-se com seu envolvimento na situação experienciada pela interagente e descreveu, então, a rotina que pretendia utilizar uma vez que as interações e mediações começassem a ocorrer regularmente:

\footnotetext{
${ }^{2}$ Tratamos o processo de mediação pedagógica em si e os reflexos de tal processo para a prática pedagógica da interagente em outros dois artigos. $\mathrm{O}$ primeiro intitulase: "O processo de mediação no Teletandem". In: BENEDETTI, A. M.; CONSOLO, D. A.; VIEIRA-ABRAHÃO, M. H. (2010); e o segundo: "Collaborative Language Learning in Teletandem: a Resource for Pre-Service Teacher Education”. Profile: Issues in Teacher's Professional Development, v. 13, n. 1, p. 139-156, April 2010.
} 
[p] retendo assistir a interação, ler o diário e confrontar a ação com a percepção. A partir disso, fazer anotações sobre os pontos positivos e os pontos problemáticos e, caso julgar necessário, buscar um texto para a leitura (e discussão posterior) que possa ajudar nas questóes problemáticas. (questionário 1, respondido por Andréa)

Durante a análise das sessões de mediação, percebemos que Andréa agiu de acordo com suas intençóes, pois notamos que ela se dedicava a estudar as interações do par sob sua responsabilidade, lendo a interação quando ela ocorria por chat ou escutando quando ocorria em áudio e fazendo um levantamento de pontos que gostaria de discutir durante a mediação.

Quanto a esses pontos levantados por ela, notamos que, no início, ela os nomeava como 'pontos positivos' e 'pontos negativos'. Entretanto, a partir da $5^{a}$ mediação, ela passa a chamar os 'pontos negativos' de 'pontos a serem discutidos'. Podemos ver, nos excertos a seguir, que os 'pontos negativos' do diário escrito antes da mediação 4 e os 'pontos a serem discutidos' escritos antes da mediação 5 versam mais ou menos sobre os mesmos temas, entretanto, são tratados sob perspectivas diferentes:

\section{Pontos negativos}

- o Tandem não está acontecendo (interação, feedback e avaliação da sessão);

- as interaçôes estão sem temas, e isto parece estar prejudicando;

- as interagentes, às vezes, pareciam ficar sem assunto;

- as interagentes pareciam já estarem cansadas em dados momento da interação (pontos levantados para a mediação 4, por Andréa).

\section{Pontos a serem discutidos}

- ainda não se cumpre o tempo determinado para cada parte da sessão tandem;

- viram a diferença entre teoria e prática: o que sentiram?;

- qual dentre as duas interaçóes, na opinião da interagente brasileira, surtiu maior resultado?;

- preparação de temas: o que sente? Está satisfatório? Falta algum recurso? (pontos levantados para a mediação 5, por Andréa).

A mediadora trata os temas de forma diferente quando se refere a eles como 'pontos a serem discutidos', colocando-os em forma de perguntas a serem feitas para a interagente, o que demonstra uma busca de envolvê-la na reflexão sobre eles, mudando sua atitude de julgadora para inquisitiva. Uma 
das razões que podemos apontar para tal mudança pode ser sua percepção, por meio das observaçôes e conversas com a interagente, de que esses pontos levantados não eram negativos, mas, sim, assuntos que deveriam ser tratados na mediação para que a interagente pudesse refletir sobre eles e entender por que razão estavam ocorrendo, como podemos comprovar neste trecho de seu diário de mediação:

Quando eu ia preparar os itens para mediação, eu primeiramente tinha que refletir sobre o que estava acontecendo, o que foi muito rico para minha formação e também para que eu realizasse conexóes teóricas que ainda não havia percebido na prática. (...) A formação é o processo de interação com um par mais competente com o devido espaço para reflexão individual. (...) Assim, eu fornecia o andaime para sua reflexão e para o seu desenvolvimento frente às próprias necessidades, tentando fornecer, ao mesmo tempo em que fornecia o andaime, espaço para seu desenvolvimento autônomo e reflexão individual, de modo a que ela alcançasse suas conclusões e, assim, se desenvolvesse (questionário final, respondido por Andréa).

Notamos, no início do excerto, que a mediadora afirmou estar aprendendo e se desenvolvendo como formadora por meio das mediações, no momento em que tomava contato com as interaçôes e pensava sobre os temas que iria propor para discussão na sessão de mediação. Seu comentário, no final do excerto, nos mostra que ela se propôs a dar um espaço maior à interagente, a fim de fomentar seu desenvolvimento e autonomia, buscando gerar reflexão, o que pode indicar que a mudança na nomeação dos pontos e na maneira de trabalhá-los durante as sessões de mediação podem advir de suas reflexões no papel de formadora.

Percebe-se, assim, que a prática da mediação, no ciclo estabelecido dentro do macroprocesso, gera oportunidades de reflexão não somente para a interagente mas também para mediadora, que expressa, no seguinte trecho de seu diário, como suas percepções são influenciadas por sua própria prática supervisa no Teletandem:

As mediações, creio eu, estão ajudando tanto a interagente em sua aprendizagem pelo tandem, quanto a mim, enquanto mediadora. Isso porque, cada vez que penso em pontos para colocar em discussão, eu mesma acabo refletindo sobre eles e criando concepçôes com a interagente. Está sendo bastante satisfatória a função de mediadora (diário de mediação 5, de Andréa). 
De uma maneira geral, o que nos parece é que a preparação da mediadora para a sessão de mediação, por meio do contato com as interações e diários da interagente, faz com que ela possa encontrar melhores caminhos para ajudar a interagente em sua prática pedagógica, partindo de acontecimentos concretos, assim como daquilo que percebe que sejam as necessidades de Dani. O comentário sobre criar concepções em conjunto com a interagente mostra a postura de colaboração estabelecida na relação entre elas.

Tal envolvimento da mediadora foi percebido pela interagente brasileira, e por ela aprovado. Ela afirma que a presença da mediadora foi fundamental para o desenvolvimento das interações e para sua percepção da relação entre teoria e prática, como se pode ver nos excertos abaixo:

A mediação é sem dúvida o momento da interação (pois acredito que seja uma continuação das interaçôes), que nos dá pistas para que possamos chegar a conclusóes acerca de nossa postura quanto a um interagente, mas também como aluno e professor. Com essas reflexões a cada nova interação nos tornamos mais capazes e com mais vontade de melhorar (diário de mediação 5, de Dani).

Achei muito produtivo o texto sobre o feedback e o relacionado com a interação com chat. É uma maneira de incorporar a teoria de forma mais produtiva, já que nossa atenção no momento da mediação está voltada totalmente para o momento da interação com a reflexão sobre que fizemos na interação (diário de mediação 7, de Dani).

Dani afirma ter gostado dos procedimentos de preparação da mediadora exatamente porque percebia que ela buscava em sua prática real na interação os pontos a serem discutidos na mediação, ou seja, ela partia da situação concreta vivida por ela nas interaçóes para debater questóes de ensino e aprendizagem e até mesmo indicar a leitura de textos teóricos que pudessem auxiliá-la. Esse envolvimento da mediadora e sua postura de abertura para ouvir a interagente pareceram contribuir para criar uma atmosfera de compromisso e confiança entre as duas.

No questionário final, ao analisar sua prática nas sessões de mediação, Andréa aponta sua preocupação com as questões estruturais da sessão como excessivas, afirmando que poderia haver trabalhado de forma diferente, o que demonstra que essa experiência prática como formadora a levou a refletir sobre seu enfoque e seus procedimentos durante o processo de supervisão: 
4) Quanto às expectativas e receios que você tinha anteriormente às sessões de mediação, você acha que elas se concretizaram? Houve algo inesperado ou que lhe surpreendeu?

Acredito que minhas expectativas foram realizadas. (...) Nas mediações, sempre me preocupei muito com a sessão tandem em si, e acho que deveria ter dado mais espaço a outros assuntos (como estratégias de ensino, por exemplo). Acredito que isso teria feito com que o tandem se realizasse sem forçar muito a reflexão sobre uma cronologia estrita.

Ainda no questionário, Andréa relata que, provavelmente influenciada por sua pesquisa também inserida no projeto Teletandem, acabou dando mais ênfase àquilo que era foco de seu estudo:

7-c) Você mudaria algo na maneira como se preparava para uma sessão de mediação? Explique.

Acho que deveria ter usado mais textos para leitura e discussão. Quando comecei a fazer isso já era um pouco tarde, creio eu. Também me preocuparia mais com o papel de professor mesmo, pois, talvez influenciada por minha pesquisa, foquei, alguma vezes, no desenvolvimento da IL de Dani e nos seus procedimentos estratégicos para se comunicar. Creio que isso faça parte também, mas acho que faltou-me olhar mais para o papel de professor (questionário 2, respondido por Andréa).

Percebemos, assim, que a experiência como mediadora no Teletandem gerou oportunidades para suas reflexões baseadas em uma situação de formação na prática durante o curso de Mestrado. Andréa passou a observar mais a relação de ensino e aprendizagem que supervisionava não somente voltada às questôes diretamente relacionadas ao seu tema de pesquisa, mas como formadora de uma professora em formação que vivenciava sua primeira experiência prática de ensino.

\section{Macroprocesso como fomentador de reflexão para a mediadora}

A experiência da mediação no Teletandem fez com que Andréa pensasse em sua própria formação enquanto formadora:

1) Como foi essa sua primeira experiência com formação de professores?

(...) Bom, para tentar percorrer o caminho rumo a uma 'melhor formação para formação de professores', já estou buscando mais embasamento teórico, o que, devo salientar, foi muito fomentado pelo contexto de mediação. Eu tinha algum conhecimento sobre desenvolvimento de aprendizagem, porém mais na perspectiva do aluno, 
sobre professor pouco eu conhecia antes do mestrado. Na mediação, pude notar e relembrar muitas coisas que vimos na disciplina de Abordagens, muitas experiências compartilhadas que me ajudaram a refletir também sobre minha prática (questionário 2, respondido por Andréa).

Como podemos ver, ela afirma que a experiência do mestrado conjugada com a função de mediadora a fizeram olhar para a formação sob a perspectiva do formador, e não somente de aluna, como fazia antes, o que a ajudou a refletir sobre sua própria prática. Todas as disciplinas que cursou durante o mestrado, as leituras e as discussões com outros mediadores nas reuniōes e com os coordenadores do projeto também funcionaram como andaimes, que certamente a auxiliaram em seu papel como mediadora, além de sua experiência como professora de línguas. Seus diários de mediação pareceram refletir o gradual aumento de reflexão proporcionado por esse conjunto de fatores, uma vez que se notou que, com o decorrer do processo, ela passou a questionar suas ações (linhas 1 a 3) e a explicitar melhor seus objetivos e motivações (linhas 3 a 5), além de explicitar algumas de suas crenças e seus próximos planos (linhas 7 a 9), como podemos ver no exemplo a seguir:

Entretanto, acho que, se continuo insistindo muito para o maior tempo de feedback e para algum tempo de avaliação, posso colocar uma camisa de força nas participantes. (...) Desde o começo do projeto, eu refletia sobre o caráter aula da interação. Talvez por minha concepção tradicional, acreditava que numa interação e consequente amizade, o caráter formal da língua e a negociação de significado seriam pouco recorrentes no contexto. Mas, cada vez que analiso, percebo que muito do que foi dado como input está sendo usado e muita informação é negociada.

Por isso, tenciono tratar mais sobre a motivação e a psicologia para professores (sem descartar o momento de feedback) e já indiquei dois textos para a interagente. Espero que consigamos refletir sobre os problemas e virtudes encontradas nas próximas interações (diário de mediação 7, de Andréa).

A experiência da mediação em si, em todo o processo de 8 meses em contato com a interagente, seja pelo visionamento das interaçóes, seja nas mediações ou nos diários, pareceram levá-la a refletir sobre suas próprias concepções de ensino e aprendizagem de línguas. No primeiro questionário respondido, antes do início das mediações, percebemos que o caráter de sua resposta é bastante teórico, provavelmente, advindo de seus estudos sobre teorias da linguagem: 
7) O que é aprender uma LE?

Aprender uma LE é como diz a hipótese de "Sapir-Worf", colocar uma lente que nos mostra a comunicação de LE como um todo diferente, com percepçôes diferentes, com objetos olhados de maneiras diferentes, como um sistema de comunicação diferente. $\mathrm{O}$ pensamento depende da linguagem e, aprender uma LE, é a remolduração de parâmetros meus, que ficam num ir e vir, "elasticamente", moldurando e remoldurando meu sistema interlinguístico. Aprender uma LE é um processo de desenvolvimento interlinguístico totalmente individual e complexo (questionário 1, respondido por Andréa).

Entretanto, ao final da experiência, ela parece bastante influenciada pela aprendizagem que observou nas interações in-teletandem:

3) Suas experiências como mediadora no Teletandem mudaram sua opinião sobre o que é ensinar e aprender uma LE? Explique.

Acredito que mudaram em relação à colaboração observada. (...) Hoje, para mim, aprender uma LE é ter a autonomia suficiente para buscar o conhecimento antes, durante e após a interação. Ou seja, acredito que as estratégias de aprendizagem jogam um papel fundamental, aliadas à autonomia e à reciprocidade (questionário 2, respondido por Andréa).

Notamos que Andréa passou a ver a questão também sob o ponto de vista que essa experiência na prática como mediadora lhe proporcionou. Sua resposta parece mostrar que a oportunidade de supervisionar um aluno em formação parece tê-la ajudado a relacionar teoria e prática na aprendizagem de línguas do ponto de vista da prática de ensino observada por ela como mediadora.

A experiência de aprendizagem docente sob a perspectiva de desenvolvimento em uma abordagem sociointeracionista contempla a interação social com um par mais competente como fonte de construção de conhecimento. O que nos pareceu dentro da relação entre a mediadora e a interagente brasileira, neste estudo, foi que o contato entre elas trouxe oportunidades de reflexão não somente para a interagente, que seria o par menos competente, mas também para a própria mediadora, o par mais competente da relação, uma vez que também foram notados em suas falas e atitudes aspectos que evidenciaram reflexão e movimentos de mudança.

Esse caráter de contribuição para a formação reflexiva do formador na prática parece ser uma característica original do contexto de Teletandem, dentro deste estudo de caso, uma vez que na mediação no Teletandem a mediadora 
(formadora em formação) passou a ter a prática de formação da interagente (aluna-professora) como guia para a busca de auxílio teórico que lhe trouxesse embasamento para entender seu papel, seus procedimentos e encontrar maneiras de melhorá-los, por meio da prática reflexiva.

A mediação no Teletandem, neste estudo de caso, apresentou pontos de semelhança e divergência em relação ao aconselhamento existente no ensino e aprendizagem em regime de tandem. A semelhança foi o caráter reflexivo dado às sessões em relação à aprendizagem e desenvolvimento da autonomia do aprendiz. A diferença é que o aconselhamento na literatura sobre tandem parece mais voltado ao auxílio ao participante em relação à aprendizagem da LE, enquanto que, neste estudo, houve também foco explícito em questões relacionadas ao ensino - possivelmente causados pelo fato de as participantes serem uma aluna-professora e uma formadora de professores em formação.

\section{Considerações finais}

O processo de mediação pedagógica e a figura do mediador incorporados ao processo do Teletandem, sob a perspectiva da formação de professores, parecem adicionar ao contexto elementos fomentadores da formação na prática de forma reflexiva, tanto para o interagente como para o mediador, configurando-se como um ambiente de construção de conhecimento, em uma perspectiva sociointeracionista, no qual há a conjugação entre teoria e prática mediada pelo uso das novas tecnologias.

Em relação ao processo de mediação, dentro da relação estudada, podemos dizer que ele incluiu elementos reflexivos, como visionamento, confecção de diários, assim como partiu da situação de prática vivenciada pela interagente dentro do Teletandem. Por parte da mediadora, o processo abarcou também estratégias pedagógicas de provimento de alternativas e postura exploratória, partindo de uma atmosfera não diretiva, o que gerou ao longo do tempo um clima de colaboração entre mediadora e interagente.

O papel do mediador dentro do contexto do Teletandem parece ir além daquele descrito na literatura de aconselhamento no ensino e aprendizagem em regime de tandem, uma vez que o auxílio ao interagente em sua prática pedagógica não se focou somente na aprendizagem da LE mas também no ensino da LM. O uso dos instrumentos mediadores, que incluíram elementos reflexivos e oferecimento de andaimes, por meio de uma postura não diretiva, levou à exploração da prática em relação às ações, decisões e procedimentos dentro do processo de ensino e aprendizagem colaborativos do Teletandem, 
trazendo para o contexto forte carga de desenvolvimento para todos os envolvidos no processo.

Desse modo, o contexto de formação na prática criado na relação entre mediador e interagente no Teletandem mostrou-se um ambiente propício a auxiliar a formação inicial (pré-serviço), tanto do aluno-professor quanto do formador de professores, advindo da possibilidade de se fazer com que a mediação seja também um trabalho colaborativo e de construção de conhecimento entre formador (mediador) e professor em formação (interagente).

A prática da mediação exercida pela formadora de professores que se encontrava em formação pareceu ser bastante positiva para a formação reflexiva do formador na prática, algo ainda um tanto quanto inexplorado na literatura da área de Linguística Aplicada. Cremos que com esse trabalho pudemos dar mais uma contribuição para a investigação sobre a formação do formador dentro de um processo reflexivo e sugerimos que outros estudos sejam conduzidos neste sentido. Acreditamos também que parcerias entre alunos de pós-graduação e graduação para trabalhos colaborativos podem auxiliar ambos em sua formação pré-serviço.

\section{Referências}

BENEDETTI, A.M.; CONSOLO, D.A.; VIEIRA-ABRAHÃO, M.H. Pesquisas em ensino e aprendizagem no Teletandem Brasil: línguas estrangeiras para todos. Campinas: Pontes, 2010.

BRAMMERTS, H. Language learning in tandem using the Internet. In: WARSCHAUER, M. (Ed.). Telecollaboration in foreign language learning: Proceedings of the Hawaii symposium. Honolulu, HI: University of Hawai'i Second Language Teaching and Curriculum Center, 1996. p. 121-130.

BRAMMERTS, H.; CALVERT, M.; KLEPPIN, K. Aims and approaches in individual learner counseling. In: LEWIS, T.; WALKER, L. (Ed.). Autonomous Language Learning In-Tandem. Sheffield, UK: Academy Electronic Publications, 2003. p. 123-130.

FIGUEIREDO, F. J. Q. A aprendizagem colaborativa: algumas considerações conceituais e terminológicas. In: FIGUEIREDO, F. J. Q. (Org.). A aprendizagem colaborativa de linguas. Goiânia: Editora UFG, 2006. p.11-45.

FREITAS, M.T.A. Vygotsky e Bakhtin. Psicologia e Educação: um intertexto. São Paulo: Ática, 2000. 
GIL, G. Mapeando os estudos de formação de professores de línguas no Brasil. In: FREIRE, M. M.; VIEIRA-ABRAHÃO, M. H.; BARCELOS, A. M. F (Org.). Linguistica Aplicada e contemporaneidade. Campinas: ALAB/Pontes, 2005. p.173-182.

GILHAM, B. Case study research methods. London and new York: Continuum, 2000.

GIMENEZ, T. Tornando-se professores de inglês: experiências de formação inicial em um curso de Letras. In: VIEIRA-ABRAHÃO, M. H. (Org.). Prática de Ensino de Lingua Estrangeira: experiências e reflexōes. Campinas: Pontes, 2004a. p.171-187.

GIMENEZ, T. Derrubando paredes e construindo pontes: formação de professores de língua inglesa na atualidade. Revista Brasileira de Linguística Aplicada, v. 4, n. 2, 2004 b.

GIMENEZ, T. Desafios contemporâneos na formação de professores de línguas: contribuições da linguística aplicada. In: FREIRE, M. M.; VIEIRA-ABRAHÃO, M. H.; BARCELOS, A. M. F (Org.). Linguistica Aplicada e contemporaneidade. Campinas: ALAB/Pontes, 2005a. p.183-201.

GIMENEZ, T. Currículo e identidade profissional nos cursos de Letras / inglês. In: TOMICH, L. M. B; VIEIRA-ABRAHÃO, M. H.; DAGHLIN, C.; RISTOFF, D. I. (Org.). A interculturalidade no ensino de Inglês. Florianópolis: UFSC, 2005b. p. 331-343.

HELMLING, B. Group work with peers: pairs advise pairs. In: LEWIS, T.; WALKER, L. (Ed.). Autonomous language learning in tandem. Sheffield, UK: Academy Electronic Publications, 2003. p.145-155.

KOHONEN, V. Experiential language learning: second language learning as cooperative learner education. In: NUNAN, D. (Ed.). Collaborative language learning and teaching. Glasgow: CUP, 1992. p.14-40.

KORTHAGEN, F. A. J. Helping student teachers to become reflective: the supervision process. In: KORTHAGEN, F. A. J. Leren reflecteren als basis van de lerarenopleiding [Learning to reflect as a basis for teacher education]. 's-Graven-hage: SVO, 1982.

KORTHAGEN, F. A. J.; KESSELS, J. P. A. M. Linking theory and practice: Changing the pedagogy of teacher education. Educational Researcher, v. 28, n. 4, p. 4-17, 1999.

KORTHAGEN, F. A. J.; KESSELS, J. P. A. M. Linking practice and theory: the pedagogy of realistic teacher education. Paper presented at the Annual Meeting of the American Educational Research Association, Seattle, April 2001. 
LANTOLF, J. P. Theoretical framework: an introduction to Vygotskian perspectives on second language research. In: LANTOLF, J. P.; APPEL, G. Vygotskian approaches to second language research. New Jersey: Ablex Publishing Corporation, 1994. p.1-32.

PAIVA, V. M. O. P. Avaliação dos cursos de Letras e a formação do professor. Revista do GELNE. João Pessoa, v. 5, n.1 e 2, p.193-200, 2004.

PAIVA, V. M. O. P. O novo perfil dos cursos de licenciatura em Letras. In: TOMICH, L. M. B; VIEIRA-ABRAHÃO, M. H.; DAGHLIN, C.; RISTOFF, D. I. (Org.). A interculturalidade no ensino de Inglês. Florianópolis: UFSC, 2005. p. 345-363.

PANICHI, L. Tandem learning and language awareness. Materials from the ALA 2002. Tandem workshop.

SALOMÃO, A. C. B. Gerenciamento e estratégias pedagógicas na mediação dos pares no Teletandem e seus reflexos para as práticas pedagógicas dos interagentes. $2008.316 \mathrm{f}$. Dissertação (Mestrado em Estudos Linguísticos) - Instituto de Biociências, Letras e Ciências Exatas, Universidade Estadual Paulista - UNESP, São José do Rio Preto, 2008.

SALOMÃO, A. C. B. Collaborative Language Learning in Teletandem: a Resource for Pre-Service Teacher Education. Profile: Issues in Teacher's Professional Development, v. 13, n. 1, p. 139-156, April 2010.

SÓL, V. S. A. A natureza da prática reflexiva de uma formadora de professores e duas professoras em formação. 2004. Dissertação (Mestrado em Linguística Aplicada) - Faculdade de Letras. Faculdade de Letras, Universidade Federal de Minas Gerais, Belo Horizonte, 2004.

SÓL, V. S. A. Modelos de supervisão e o papel do formador de professores. Contexturas. APLIESP, São Paulo, n. 8, 2005.

SOUZA, R. A. Telecolaboração na aprendizagem de línguas estrangeiras: um estudo sobre o regime de tandem. In: FIGUEIREDO, F. J. Q. A. A aprendizagem colaborativa de linguas. Goiânia: Editora UFG, 2006. p. 255-276.

STICKLER, U. Student-centred counselling for tandem advising. In: LEWIS, T.; WALKER, L. (Ed.). Autonomous language learning in tandem. Sheffield, UK: Academy Electronic Publications, 2003. p.115-122.

TELLES, J.A.; VASSALLO, M.L. Foreign language learning in-tandem: Teletandem as an alternative proposal in CALLT. The ESPecialist, v. 27, n. 2, p. 189-212, 2006. 
VASSALLO, M. L.; TELLES, J. A. Foreign language learning in-tandem: Theoretical principles and research perspectives. The ESPecialist, v. 27, n. 1, p. 83-118, 2006.

VIEIRA-ABRAHÃO, M. H. (Org.). Prática de Ensino de Lingua Estrangeira: experiências e reflexões. Campinas: Pontes, 2004.

VIEIRA-ABRAHÃO, M. H. A construção da prática de sala de aula de línguas e a formação e o desenvolvimento do professor. In: SEMINÁRIO DE LÍNGUAS ESTRANGEIRAS, 6, 2005, Goiânia. Anais... Goiânia: UFG, 2005.

VIEIRA-ABRAHÃO, M.H. The construction of theoretical and practical knowledge in initial education. Profile: Issues in Teachers' Professional Development. Universidade Nacional da Colômbia, v. 7, p. 87-99, 2006.

VYGOTSKY, L.S. The genesis of higher mental functions. In: WERTSCH, J. V. (Ed.). The concept of activity in Soviet psychology. New York: M. E. Sharpe, 1981. p.144-188.

VYGOTSKY, L. S. A formação social da mente. São Paulo: Martins Fontes, 1994.

WALKER, L. The role of the tandem learner diary in supporting and developing learner autonomy. In: LEWIS, T.; WALKER, L. (Ed.). Autonomous language learning in tandem. Sheffield, UK: Academy Electronic Publications, 2003. p.131-144.

Recebido em 06/07/2010. Aprovado em 21/02/2011. 